\title{
STUDY ON MULTIPOTENT MEDICINAL ASPECTS OF SCHIMA WALLICHII (BARK) FROM NAGALAND, NE INDIA
}

\section{MINAKSHI BHATTACHARJEE*, VITOLU SEMA Y, MANASH PRATIMSARMA}

Department of Biotechnology, Assam Down Town University, Guwahati, Assam, India. Email: minakshibhattacharjee2007@gmail.com Received: 23 September 2018, Revised and Accepted: 23 November 2018

\begin{abstract}
Objective: The present study focuses on the multipotent medicinal aspects of Schima wallichii bark.

Methods: The ethanol and water extracts of the plant were investigated its phytochemical, antibacterial, antioxidant, and anticoagulant as per the standard method.

Results: S. wallichii bark extract was effective against Staphylococcus aureus. It was also found to be a good antioxidant having an $\mathrm{IC}_{50}$ value of 98.7 in ethanolic extract. Further, the water extract increased in prothrombin time to $57.7 \mathrm{~s}$ against normal (12.3 s). The different phytochemicals, namely tannin, saponins, steroids, terpenoids, flavonoids, and glycosides, were present. Since the findings showed very less percent inhibition in comparison to curcumin-treated cells, thus both the extracts were both not effective in the antiproliferative assay.
\end{abstract}

Conclusion: We conclude that this plant is a good candidate for developing a natural drug.

Keywords: Schima wallichii, Antioxidants, 2,2-diphenyl-1-picrylhydrazylhydrate, Phytochemicals, Anticoagulase, Antimicrobial.

(C) 2019 The Authors. Published by Innovare Academic Sciences Pvt Ltd. This is an open access article under the CC BY license (http://creativecommons. org/licenses/by/4. 0/) DOI: http://dx.doi.org/10.22159/ajpcr.2019.v12i3.29288

\section{INTRODUCTION}

The uses of various plants as medicines have come a long way of centuries of experimentation on humans based on trial and error, leading to the development of many traditional medicine systems that are in vogue in the modern world [3]. Many researchers have shown keen interest in studying potentiality of medicinal plants and their phytochemical analysis [4,5]. In India, the state of Nagaland $\left(26.1584^{\circ} \mathrm{N}, 94.5624^{\circ} \mathrm{E}\right)$ situated in the northeastern region is one of the two biodiversity hotspots of eastern Himalayas, which, in turn, comes under the 35 biodiversity hotspots identified globally [1]. There are approximately 16 tribal groups inhabiting these regions having their different dialects [2]. These indigenous people have been practicing the use of plant and their parts as medicine to heal a lot of health problems in their traditional therapeutic system. Schima wallichii belonging to the family Theaceae is one of the plants used by Sema tribe of Nagas, as antiseptic in wounds and for other disease condition, but there is very little information regarding the scientific validation of the plant in India. It is an evergreen tree and is found in northern Indian, Nepal, Bhutan, southwestern China (Tibet, Yunnan, Guizhou, and Guangxi), Myanmar, Thailand, Laos, and Vietnam which grows up to 10-20 m tall. The astringent corollas are used to treat uterine disorders and hysteria. The crude drug prepared from this plant is known as "buah cangkok" in Indonesia and "changkoh" in Peninsular Malaysia [6]. The present study focuses on the antimicrobial, anticoagulant, and antioxidant properties of $S$. wallichii (bark).

\section{METHODS}

\section{Extraction}

The plant sample was collected from the hilly forest of Philimi Village, Zunheboto, Nagaland, India (Fig. 1a-c). The geographical coordinates, i.e., latitude and longitude of Philimi Village are $26.0078836 \mathrm{~N}$ and 94.5195866E, respectively. The tree bark was collected during the month of February 2017. The plant material was identified by Mr. Inaje Phuleshe, Project Director, District Rural Development Agency (DRDA) and authenticated by Deputy Range Officer, Mr. Khuhevi Aye,
Dimapur Division, Nagaland. The bark was cleaned and shade dried at room temperature in clean and hygienic conditions. The dried bark was powdered using mortar and pestle and extracted sequentially with ethanol and water. $500 \mathrm{~g}$ of the tree bark was completely extracted by maceration using the solvents at room temperature to obtain ethanol and aqueous extracts, respectively.

\section{Phytochemical screening $[7,8]$}

The screening of the following phytoconstituents was performed as per standard protocol.

\section{Saponins}

Few $\mathrm{ml}$ of the extract was taken in $10 \mathrm{ml}$ of water and shaken vigorously; formation of bubbles observed or persistent foam which indicates the presence of saponins.

\section{Tannins}

Few $\mathrm{ml}$ of the extract was treated with 3-4 drops of $10 \%$ alcoholic ferric chloride; formation of brownish-blue or black color indicates the presence of tannins.

\section{Flavonoids}

Few ml of the extract was treated with 1-2 drops of sulfuric acid; formation of intense yellow color is observed. To this dilute acid is added, but there was no disappearance of the yellow color.

\section{Phenols}

To $2 \mathrm{ml}$ of extract, $2 \mathrm{ml}$ of aqueous ferric chloride was added. Formation of blue color indicates the presence of phenols.

\section{Terpenoids}

Take $1 \mathrm{ml}$ of extract and add $0.5 \mathrm{ml}$ of chloroform followed by a few drops of concentrated sulfuric acid; formation of reddish-brown precipitate indicates the presence of terpenoids. 


\section{Glycosides}

To $1 \mathrm{ml}$ of each extract, $0.5 \mathrm{mg}$ of glacial acetic acid and three drops of $1 \%$ aqueous ferric chloride solution was added; formation of brown ring at the interface indicates the presence of glycosides.

\section{Steroids}

About $1 \mathrm{ml}$ of extract dissolved in $10 \mathrm{ml}$ of chloroform and equal volume of concentrated $\mathrm{H}_{2} \mathrm{~S} 04$ was added by the sides of the test tube. The upper layer turns red and sulfuric acid layer shows yellow with green fluorescence. This indicates the presence of steroids.

\section{2,2-diphenyl-1-picrylhydrazylhydrate (DPPH) assay}

DPPH scavenging activity of ethanol and aqueous extract of the bark was assayed according to the method of Kaur and Mondal [9]. The preparation of test solution with different concentration of the plant sample $(10 \mu / \mathrm{ml}-160 \mu / \mathrm{ml})$ was done from a concentration of $1000 \mu \mathrm{g} / \mathrm{ml}$ by making the total volume up to $1 \mathrm{ml}$ with distilled water, then after $2 \mathrm{ml}$ of methanolic DPPH solution and the final volume is made to $3 \mathrm{ml}$. The absorbance was determined by absorption at $517 \mathrm{~nm}$ after $30 \mathrm{~min}$ against a blank solution containing methanol without DPPH. Ascorbic acid was taken as standard. $\mathrm{IC}_{50}$ values were calculated online using AAT BioQuest software and the data were represented graphically. The percentage inhibition was also calculated as per the following formula:

Percentage RSA I $\%=\frac{\text { Abs control }- \text { Abs sample }}{\text { Abs control }} \times 100$

Where, RSA is the radical scavenging activity, Abs control is absorbance of DPPH radical+methanol, and Abs is absorbance of DPPH radical+bark extract.

\section{Antibacterial assay [10]}

A hospital isolate of Staphylococcus aureus was obtained from Down Town Hospital, Guwahati. Antibacterial test was performed by agar well diffusion method. Bacteria suspension was enriched in brain heart infusion broth for overnight. Cultures of $0.5 \mathrm{McFarland}$ were aseptically swabbed over sterile cork borer, the agar gel was punctured; $100 \mu \mathrm{l}$ of plant extract was pipetted into the wells. Only dimethyl sulfoxide served as control. Inoculated plates were incubated at $47^{\circ} \mathrm{C}$ for overnight. The zone of inhibition formed around the wells was measured. Plates were prepared in triplets and the mean diameter of the zone of inhibition was noted.

\section{Coagulation assay [11]}

\section{Protime/prothrombin time}

Prothrombin time was calculated using PT/INR m. $100 \mu$ l of normal control (commercial, pooled plasma) was pipetted out in each of the test tubes and allowed at least $1 \mathrm{~min}$ to reach $37^{\circ} \mathrm{C} .200 \mu \mathrm{l}$ of PT reagent (Thrombore ${ }^{\circledR} \mathrm{S}$ reagent) was pipetted out into the tube containing the control and the stopwatch was started simultaneously. The tubes were mixed and left in the water bath for a minimum of 7-8 s. They were removed, tilted back and forth gently until a visible clot was formed. A visible clot was formed which would eventually gelatinize and turn cloudy. The watch was stopped and the result was recorded. The procedure was repeated for the blood samples (one part of sodium citrate solution $[0.11 \mathrm{~mol} / \mathrm{L}]$ to nine parts of venous blood, avoiding the formation of foam) containing the plant extract and the time was recorded. The reference range was 11.0-13.0 s.

\section{RESULTS}

\section{Phytochemical screening}

Phytochemical screening (Table 1) of S. wallichii of ethanol and water extracts showing the following result.

Phytochemical screening of $S$. wallichii bark extract was performed ethanol and water extracts of the bark showed the presence of various phytochemicals such as tannins, steroids, flavonoids, phenol, and phenolic compounds.
IC $_{50}$ calculation

The $\mathrm{IC}_{50}$ calculation for ethanol extract value is 98.7 and $\mathrm{IC}_{50}$ value for water is 257 (Fig. 2a and b).

\section{Anticoagulation test}

The blood sample was first treated with control reagent. The time taken for blood sample to clot was $12.3 \mathrm{~s}$. On the second step, the extract (aqueous) along with the reagent was treated and the time taken was $57.7 \mathrm{~s}$ (Fig. 3a and b). This interprets that the alcohol extract of S. wallichii has some anticoagulant property.

\section{DPPH assay}

The DPPH assay activity is shown in Fig. 4.

\section{Antibacterial activity}

In vitro antibacterial activity was examined for alcohol extracts. Both ethanol and water extract produced a zone of inhibition and were measured (Fig. 5a and b).

Antibacterial potential of extracts was assessed in terms of zone of inhibition $(\mathrm{mm})$ of bacterial growth. The results of the antibacterial activities are presented in Table 2 . The assaying of the inhibitor effect on the effect of different concentrations of the bark extract on the radial growth of S. aureus was assessed in vitro.

Obvious inhibitory effect (Fig. 6) was observed and inhibition level increased with the increase of extract concentration. The present findings showed that percent inhibition was very less in comparison to curcumin-treated cells. Hence the ethanol extract as well as water extract was both not effective in the anti-proliferative assay or MTT assay [12].

\section{DISCUSSION}

The uses of natural drugs are often encouraged as they are safer, non-toxic than allopathic drugs. The use of phytoceuticals is an age-old practice in the civilization of India. It is credible to observe these natural healing practices, particularly in rural/tribal communities in India. In this study, we have reported on the various medicinal aspects of $S$. wallichii which was brought from an interior village in Nagaland. The Sema tribe of Nagas uses this plant mostly as antiseptic in wounds. Very less information is available from other parts of India. Therefore, we attempted to analyze phytochemical constituents, antioxidants, antimicrobial, and anticancer properties of this plant. Lalrinzuali et al. [13] have reported its uses to treat snake/insect bites and antiseptic properties of fruits. The bark powder is used to treat gastric problems.

Table 1: Phytochemical screening results

\begin{tabular}{lll}
\hline Phytochemical & $\begin{array}{l}\text { S. wallichii ethanol } \\
\text { extract }\end{array}$ & $\begin{array}{l}\text { S. wallichii water } \\
\text { extract }\end{array}$ \\
\hline Saponin & Present & Present \\
Steroids & Present & Present \\
Terpenoids & Present & Present \\
Flavonoids & Present & Present \\
Tannins & Present & Present \\
Glycosides & Present & Present \\
Phenols and phenolic & Present & Present
\end{tabular}

compound

S. wallichii: Schima wallichii

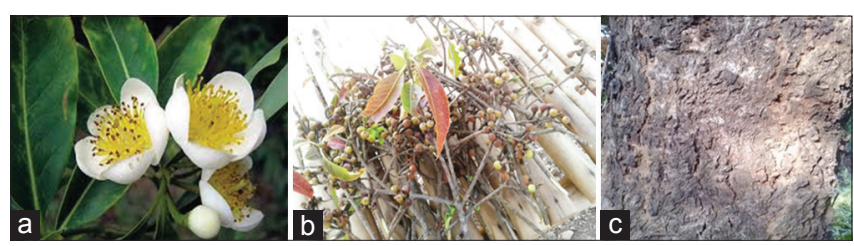

Fig. 1: (a) Schima wallichii flower, (b) stem, leaves, and fruit, (c) bark 


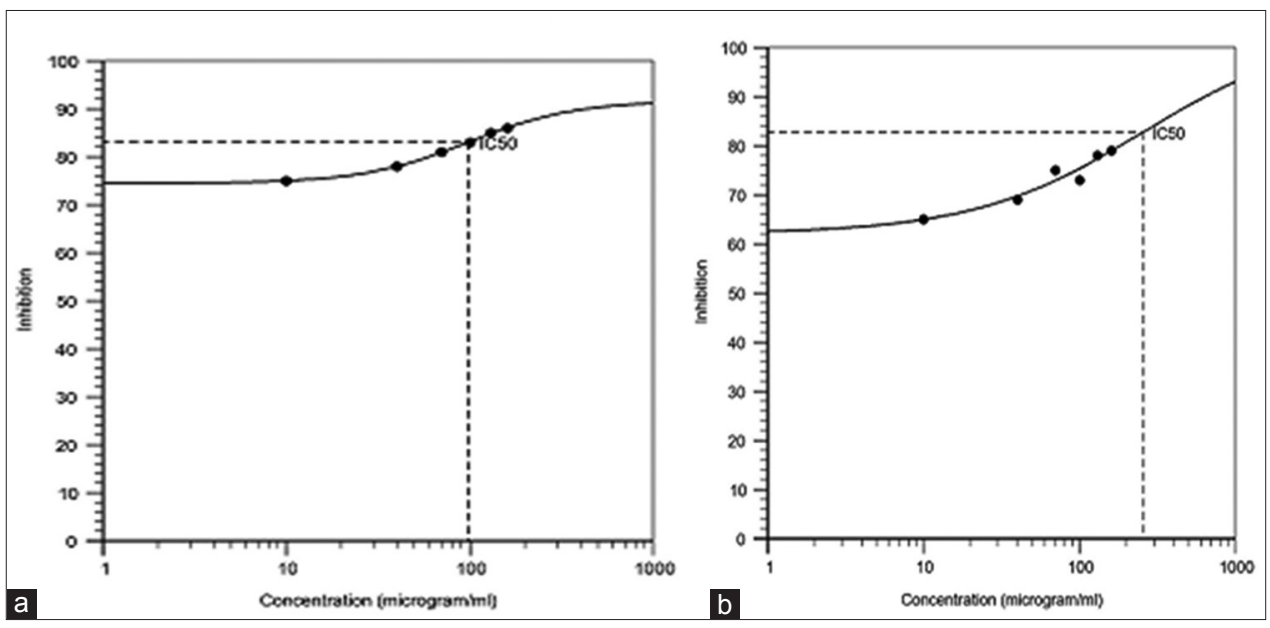

Fig. 2: ( $a$ and b) $I_{50}$ values for ethanol and water extract
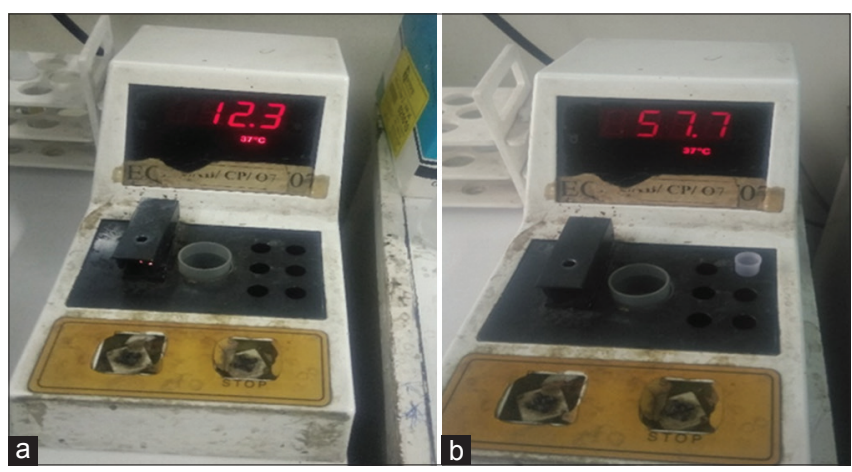

Fig. 3: (a) Normal clotting time, (b) clotting time after adding extract

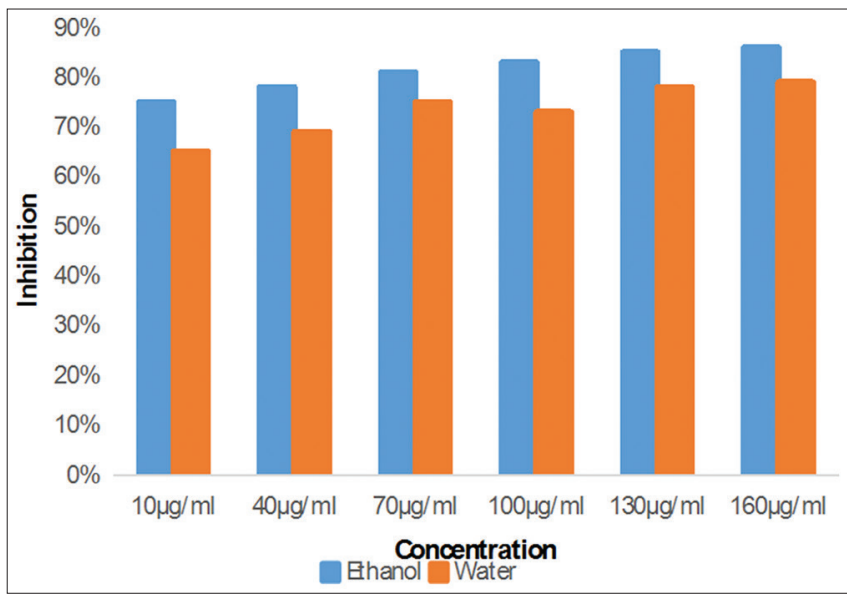

Fig. 4: 2,2-diphenyl-1-picrylhydrazylhydrate scavenging activity

The manifestations of a blood clot range from kidney failure, pulmonary embolism, deep vein thrombosis, pregnancy complications, etc., and some natural blood thinners are documented such as turmeric, ginger, cinnamon, and cayenne peppers. One important aspect is that it is necessary to maintain the dosage of the chemical blood thinners, and there is a thin line between blood clotting and bleeding for people using these anticoagulant medicines such as warfarin and antiplatelet drugs such as aspirin [14]. The advantage of preferring natural drugs over the synthetic ones is well established. Our extract showed high prothrombin time (57.7 s) against normal clotting time of $12.3 \mathrm{~s}$.

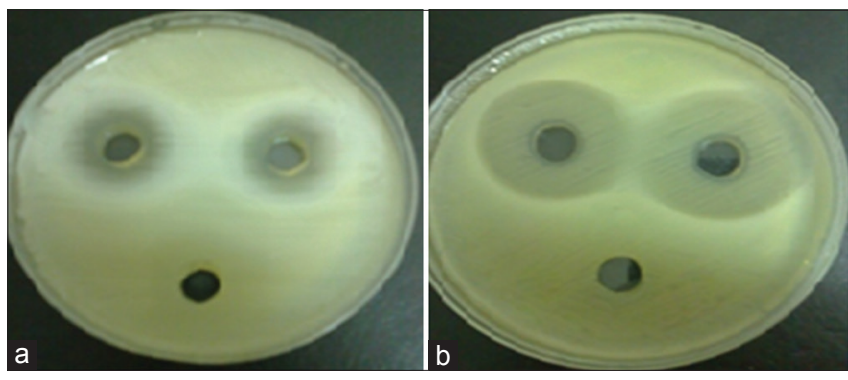

Fig. 5: Antibacterial activity (a) Ethanol extract, (b) water extract

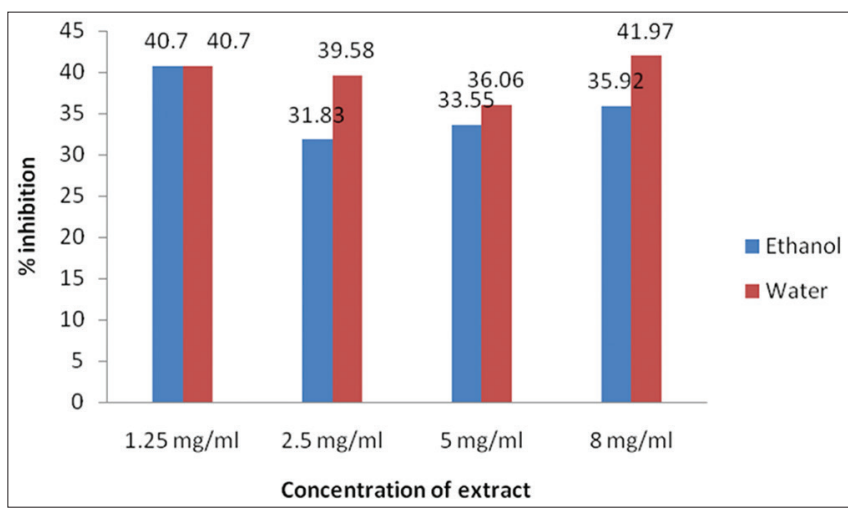

Fig. 6: Extracts inhibition percentage

Table 2: Antibacterial activity (zone of inhibition)

\begin{tabular}{lll}
\hline S. aureus & Ethanol extract $(\mathbf{m m})$ & Water extract $(\mathbf{m m})$ \\
\hline $100 \mathrm{CFU} / \mathrm{ml}$ & 12.3 & 16.4 \\
$50 \mathrm{CFU} / \mathrm{ml}$ & 11.2 & 15.5 \\
\hline
\end{tabular}

S. aureus: Staphylococcus aureus

Among the water and ethanolic extracts, the water extract showed higher antimicrobial activity against hospital isolated strain of $S$. aureus. Saikat et al., 2008 [15], evaluated the bark extract of $S$. wallichii against a range of Gram-positive and Gram-negative bacteria and few fungal pathogens. The hydroethanolic extract showed the highest activity against Gram-negative bacteria such as Escherichia coli, Pseudomonas aeruginosa, and Shigella sp. It was less effective against Gram-positive bacteria Sarcina lutea, Bacillus pumilus, and Bacillus subtilis. The extract was also effective against Candida albicans. Our study showed the 
antibacterial activity against a hospital isolate of $S$. aureus strain which is added knowledge of its effectiveness against pathogenic strains.

The bark of $S$. wallichii when subjected to qualitative phytochemical screening contained several secondary metabolites. The different phytochemicals, namely tannin, saponins, steroids, terpenoids, flavonoids, and glycosides, were present. Moreover, a high antioxidant activity has been recorded in the ethanolic extract showing an $\mathrm{IC}_{50}$ value of 98.7.

Many plant compounds have been reported to scavenge DPPH radicals in vitro. Different extracts of $S$. wallichii scavenged DPPH radicals in a concentration-dependent manner. Kaempferol flavonoid present in S. wallichii scavenged $\mathrm{OH}$ radicals according to an earlier study $[15,16]$. The exact mechanism of free radical scavenging by different extracts of $S$. wallichii is not known. However, the phytochemical analysis of $S$. wallichii bark has shown the presence of phenols and flavonoids. The concentrations increased in a concentration-dependent manner. Therefore, antioxidant activities of $S$. wallichii could be attributed to various polyphenols and flavonoids present. Unlike the findings of Lalhminghlui et al. [17] who reported anticancer activity of $S$. wallichii we did not find the same in our sample.

The effectiveness of the extract could be further evaluated by fractionating and purifying compounds from the said plant using standard protocols.

\section{CONCLUSION}

The present study concludes that $S$. wallichii is bestowed by nature with multipotent qualities as antimicrobial, anticoagulant, and antioxidant and, therefore, could be developed into a standard natural drug.

\section{ACKNOWLEDGMENT}

The author thanks Assam Down Town University for the research support, Mr. Inaje Phuleshe, Project Director, DRDA, Zunheboto, Nagaland, Mr. Khkekato Swu, and Mr. Khuhevi Aye, Deputy Range Officer, for providing and identifying the plant sample.

\section{AUTHORS' CONTRIBUTIONS}

- Minakshi Bhattacharjee and Manash PratimSarma wrote the manuscript

- Y Vitolu Sema did the experiments.

\section{CONFLICTS OF INTEREST}

The authors declare that there are no conflicts of interest.

\section{REFERENCES}

1. Available from: http://www.kerenvis.nic.in/Database/Hotspot_1804. aspx. [Last accessed on 2018 Jun 26].

2. Shimray UA. Naga Population and Integration Movement. New Delhi: Mittal Publications; 2007. p. 25-33.

3. Cragg GM, Newman DJ. Natural products: A continuing source of novel drug leads. Biochim Biophys Acta 2013;1830:3670-95.

4. Saranya TK, Gowrie SU. Phytochemical analysis and in vitro studies on antibacterial, antioxidant and anti-inflammatory activities using Casuarina equisetifolia bark extracts. Int J Pharm Pharm Sci 2017; 10:118-25.

5. Bair S, Remakanthan A, Kumar HH, Aryakrishna UK. Comparative study of the phytochemicals, antioxidant and antibacterial potential of methanolic extracts of Trichosanthes cucumerina (1) Var Cucumerina under in vitro culture and natural conditions. Int J Pharm Pharm Sci 2017; 10:147-54

6. Min T, Bartholomew B. Schima wallichi Missouri Botanical Garden, Flora of China. St Louis MO. China, Cambridge, MA: Harvard University Herbaria; 2014.

7. Trease G, Evans SM. Pharmacognosy. $15^{\text {th }}$ ed. London: Bailer Tindal; 2002. p. 23-67.

8. Harbourne JB. Phytochemical methods a Guide to Modern Techniques of Plant Analysis. $2^{\text {nd }}$ ed. London: Chapman and Hall; 1984. p. 4-16.

9. Kaur S, Mondal P. Study of total phenolic and flavonoid content, antioxidant activity and antimicrobial properties of medicinal plants. J Microbiol Exp 2014;1:23-8.

10. Bauer AW, Kirby WM, Sherris JC, Turck M. Antibiotic susceptibility testing by a standardized single disk method. Am J Clin Pathol 1966;45:493-6.

11. Miale JB. The fibrometer system for routine coagulation tests: Prothrombin time and partial thromboplastin time, macro and micro. Am J Clin Pathol 1965;43:475-80.

12. Berridge MV, Herst PM, Tan AS. Tetrazolium dyes as tools in cell biology: New insights into their cellular reduction. Biotechnol Annu Rev 2005;11:127-52

13. Lalrinzuali K, Vabeiryureilai M, Chandra G. Ethnomedicinal use and phytochemical analysis of selected medicinal plants of Mizoram India. Trends Green Chem 2015;1:1-9.

14. Available from: https://www medlineplus.gov.bloodthinners.html. [Last accessed on 2018 Jun 26].

15. Saikat D, Anup M, Rupa M, Avijit M, Subhash MC. Evaluation of antimicrobial activity of hydroalcoholic extract Schima wallichii bark. Pharmacology 2008;1:523-8.

16. Shantabi L, Jagetia GC, Vabeiryureilai M, Lalrinzuali K. Phytochemical screening of certain medicinal plants of Mizoram, India and their folklore use. J Bio Biopros Dev 2014;1:136.

17. Lalhminghlui K, Chandra JG. Evaluation of the anticancer activity of chilauni, Schima wallichii (DC.) Korth. In vitro. Int Res J Pharm Biosci 2017;2017:30-51. 